\title{
Diagnóstico da qualidade da água do rio Parauapebas (Pará - Brasil)
}

\author{
Gilmar W. SIQUEIRA' ${ }^{1}$, Fabio APRILE ${ }^{2, *}$, Antonio Miguel MIGUÉIS²
}

\section{RESUMO}

O objetivo desta pesquisa foi desenvolver um diagnóstico da qualidade da água do rio Parauapebas (Estado do Pará, Brasil), com base no monitoramento realizado nos períodos de baixa precipitaçáo dos anos 2004, 2007 e 2009. Em 20 locais de amostragem ao longo do rio no entorno da cidade de Parauapebas, foram avaliados na água parâmetros físicos (transparência, temperatura da água e resíduo total), químicos (oxigênio dissolvido, pH, turbidez, alcalinidade, dureza, acidez, cloreto, DBO, DQO e fósforo, ferro e nitrogênio totais) e biológicos (coliformes termotolerantes). A partir dos resultados foi desenvolvido o Índice de Qualidade de Água - IQA para o trecho monitorado. Para interpretação dos dados realizou-se estudos complementares de análise de componentes principais, regressão múltipla e regressão linear, além de levantamentos de informaçôes a respeito dos meios físicos, bióticos e sócio-econômicos da regiáo. O IQA determinado para o rio Parauapebas foi de 40,01 o que o enquadra na categoria "Regular". Com as análises de componentes principais e de regressão múltipla identificaram-se quatro variáveis que influenciaram significativamente na variação do índice: oxigênio dissolvido, demanda bioquímica do oxigênio, fósforo total e coliformes termotolerantes, que explicaram $75 \%$ da variação dos resultados. A expansão urbana, especialmente nas direçóes N-NO e S-SO, atingiu as áreas próximas às reservas de mata ciliar, comprometendo, em parte, a qualidade das águas superficiais do rio Parauapebas.

PALAVRAS-CHAVE: Índice de Qualidade da Água; coliformes termotolerantes; esgoto doméstico; saneamento; Amazônia.

\section{Diagnostic of the water quality of the Parauapebas River (Pará, Brazil)}

\section{ABSTRACT}

The objective of this research was to develop a diagnostic of the water quality of the Parauapebas River (Pará, Brazil), in the dry periods of 2004, 2007 and 2009. In 20 sampling sites in Parauapebas River, around of the Parauapebas City, physical (transparency, water temperature and total solid residues), chemical (dissolved oxygen, $\mathrm{pH}$, turbidity, alkalinity, hardness, acidity, chloride, Biochemical Oxygen Demand, Chemical Oxygen Demand, total phosphorus, total iron and total nitrogen), and biological parameters (thermotolerant coliforms) were measured. The results were used for the determination of Water Quality Index (WQI). As support to the interpretation of these parameters, a Principal Components Analysis (PCA), multiple regression and linear regression analyses and, a general survey of physical, biotical and social-economic of the region were performed. WQI for the Parauapebas River, in the monitored area, was 40.01, which classifies it in the category "Regular". The PCA and multiple regression analysis identified four parameters that have been employed in the WQI determination and that influenced significantly the variation of the Index: dissolved oxygen, BOD, total phosphorus and thermotolerant coliforms, which explained $75 \%$ of the variation of the results. The results indicate that the urban expansion, in especial in the directions N-NW and S-SW, has reached the areas surrounding the Riparian Forest, and affected partially the surface water quality of the Parauapebas River.

KEY-WORDS: river basin; Water Quality Index; faecal coliforms; domestic sewage; sanitation; Amazonian.

\footnotetext{
${ }^{1}$ Departamento de Química, Universidade Federal do Pará. Av. Augusto Corrêa n. 1, Campus Universitário do Guamá, 66075-100 Belém, PA, Brasil. Fone: (91)32017910. E-mail: gilmar@ufpa.br;

${ }^{2}$ Laboratório de Biologia Ambiental, Universidade Federal do Oeste do Pará, Av. Marechal Rondon s/n Caranazal, 68040-070 Santarém, PA, Brasil. Fone: (93)30649066. E-mail: aprilefm@hotmail.com; miguelmigueis@gmail.com

${ }^{*}$ Correspondence author.
} 


\section{INTRODUÇÃO}

A água constitui-se um elemento indispensável à sobrevivência de todos os organismos vivos, além disso, é extremamente importante para a manutençáo do clima na Terra. A água pode apresentar qualidades variáveis, dependendo do local e das condiçôes de sua origem. O suprimento de água doce de boa qualidade é essencial para o desenvolvimento econômico, para a qualidade de vida das populaçóes humanas e para a sustentabilidade dos ciclos dos nutrientes no planeta (Tundisi 2003).

A região Amazônica se destaca pela imensa disponibilidade hídrica, que pode variar, dependendo da Unidade da Federação, da ordem de $100.000 \mathrm{~m}^{3}$ hab $^{-1}$ ano $^{-1}$ a 1.000 .000 $\mathrm{m}^{3} \mathrm{hab}^{-1}$ ano $^{-1}$, enquanto que a média nacional brasileira situase próximo de $50.000 \mathrm{~m}^{3} \mathrm{hab}^{-1} \mathrm{ano}^{-1}$ (Goulding et al. 2003).
Nos últimos anos, entretanto, em virtude do crescimento populacional aliado ao desenvolvimento urbano, tem ocorrido a diversificação dos usos da água na região amazônica, gerando um aumento do despejo de efluentes e resíduos sólidos e a destruição das matas ciliares, produzindo condiçóes ambientais inadequadas. Como resultado das atividades antrópicas, pode haver o surgimento de doenças de veiculação hídrica, bem como degradação dos mananciais. Muito pouco se tem feito para conservar esse importante recurso natural. Estima-se que, na América Latina, apenas 2\% das águas residuárias são tratadas (ANA 2002; 2005) antes de serem servidas à população.

O rio Parauapebas (Figura 1), localizado no centro-sul do Estado do Pará e cortando o município de mesmo nome, é responsável pelo fornecimento de água para quase a totalidade

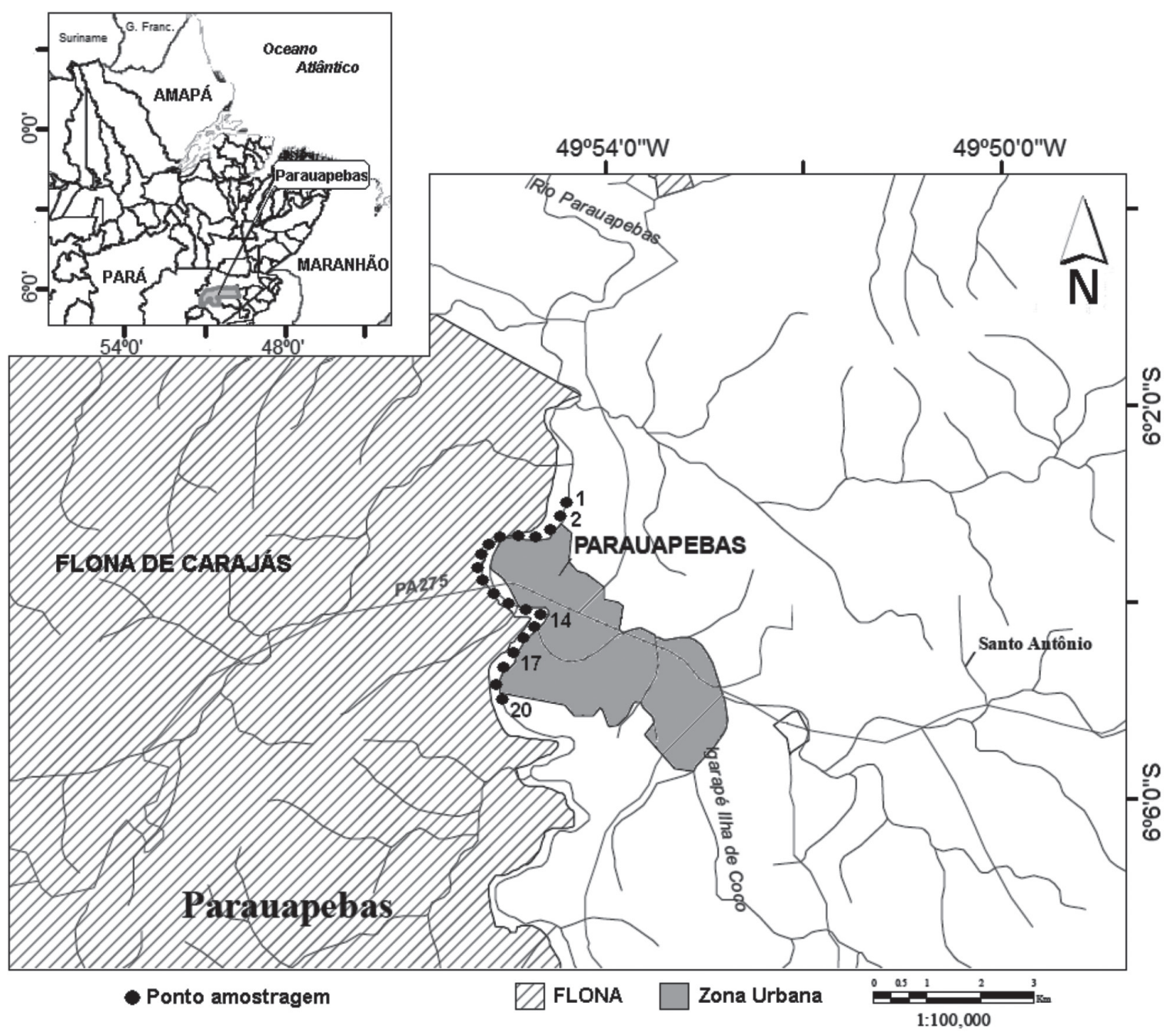

Figura 1- Localização da bacia do rio Parauapebas no trecho amostrado contendo os pontos de coleta e área do município de Parauapebas, Centro-Sul do Estado do Pará, Amazônia, Brasil. (Fonte: Base de Dados SIPAM e IBGE escala original 1:250.000). 
do abastecimento público da cidade, além de servir como fonte de recreação e pesca. Apesar disso, nota-se náo haver uma preocupação com relaçẫo à preservação e conservação ambiental do rio, visto ser observada, no trecho estudado, uma ocupaçáo das margens gerando conflitos sociais e, principalmente, ambientais. Com a ocupação nota-se a modificação da mata ciliar, extraçáo de pedra e areia para construção civil e, o lançamento de resíduos sólidos e efluentes às suas margens. Com base nesse quadro, como se encontra a qualidade da água do rio em face da expansão urbana às suas margens nos últimos anos? A qualidade da água do rio Parauapebas à luz da Resoluçáo Conama no 357 (Conama, 2005), que estabelece padróes de lançamento de efluentes, tem se deteriorado nos últimos anos? Uma vez que o trecho de rio estudado atua como corpo receptor de águas pluviais e esgotos domésticos, oriundos do município instalado no entorno, qual é a capacidade de auto-depuração de suas águas? Para responder tais questionamentos, este trabalho visou avaliar a qualidade ambiental do rio Parauapebas através da análise de parâmetros físicos, químicos e biológicos da água.

O município de Parauapebas foi criado em 1988, e atualmente possui uma área de aproximadamente 6928 $\mathrm{km}^{2}$, dos quais a Cia. Vale do Rio Doce (CVRD), os índios Xicrins do Cateté, e o Governo Federal, através de projetos de preservação ambiental (APA - Área de Proteção Ambiental, Rebio - Reserva Biológica e Flonata - Floresta Nacional do Tapirapé) detêm a concessão de $80 \%$ do total dessa área. $\mathrm{O}$ município engloba as principais elevaçóes que compóem a Serra dos Carajás. Este complexo montanhoso, onde se registram grandes ocorrências minerais, é composto pelos maciços de Serra Norte, Serra Sul, Serra Arqueada, Serra de Redençáo e Serra do Cinzento, situadas a oeste do rio Parauapebas (margem esquerda) e Serra do Buriti ou do Rabo, e Serra Leste ou Sereno, e Serra do Paredão, a leste do mesmo rio. As Serras Leste ou Sereno, onde se situa Serra Pelada, e as Serras do Paredão da Redençáo e do Cinzento, estão fora do Município (PMP 2009).

Localizado na chamada "Zona Tropical", o município de Parauapebas apresenta dois subtipos de clima, o de planícies e o de montanhas, ambos de acordo com a classificaçáo do Köppen incluídos como clima "Am" tropical, quente e úmido, com precipitação elevada. A estaçáo seca ocorre entre maio e novembro. No período de chuvas, regionalmente conhecido como "inverno", a precipitação pode alcançar $2800 \mathrm{~mm}$ e a umidade relativa do ar chega a ultrapassar $90 \%$. A temperatura média ao longo do ano é de $29^{\circ} \mathrm{C}$. Segundo Censo 2010 Primeiros Resultados (IBGE, 2010; PMP, 2009), a população do município é de 101.440 habitantes, sendo que a área urbana (em destaque na Figura 1) concentra 54.729 pessoas ou $53,95 \%$ da população total.
O município de Parauapebas é banhado pelos rios Parauapebas e Itacaiúnas, ambos com nascentes na Serra Arqueada e correndo na direção S-N. O rio Parauapebas (Figura 1) é formado pela junção do Ribeirão do Caracol e do Córrego da Onça, sempre correndo na direção S-N, recebendo pela margem esquerda os rios Córrego da Goiaba, Rio Sossego, Igarapé da Gal, Rio Gelado e Rio Sapucaia; e pela margem direita os rios Plaquê, Verde, Novo e Caracol e o Igarapé Ilha do Coco, que deságua no Rio Verde. O rio Parauapebas só é navegável por pequenas embarcaçôes em trechos freqüentemente interrompidos por corredeiras e pequenas cachoeiras.

\section{MATERIAL E MÉTODOS}

Foram selecionados 20 pontos ao longo do rio Parauapebas, no trecho de maior urbanização distanciados em cerca de 400 $\mathrm{m}$ entre cada ponto, tendo extensão de aproximadamente 8 km (Figura 1). Todo mês de setembro dos anos de 2004, 2007 e 2009, durante o período de menor precipitação na regiáo e fluxo básico do rio, águas superficiais $(0,10 \mathrm{~m})$ foram coletadas contra a corrente, armazenadas em frascos de polietileno de $1.000 \mathrm{~mL}$ e conservadas em caixa refrigerada até a chegada no Laboratório de Química da UFPA, onde se procedeu à realização das análises. Optou-se por fazer as coletas durante a baixa precipitação especialmente devido à dificuldade em acessar determinados trechos da bacia durante os períodos de chuva. O protocolo analítico da Normalização Técnica da Companhia de Tecnologia e Saneamento Ambiental do Estado de São Paulo - Cetesb (1988) foi utilizado como metodologia nas coletas das amostras. A transparência da água (m) foi determinada com um disco de $\operatorname{Secchi}(\Phi=30 \mathrm{~cm})$; as medidas de temperatura da água $\left({ }^{\circ} \mathrm{C}\right), \mathrm{pH}$, oxigênio dissolvido $(\mathrm{OD}$ $\mathrm{mg} \mathrm{L}^{-1}$ ), saturaçáo do oxigênio (\%) e turbidez (UNT) foram realizados no campo com auxílio de sondas multiparâmetros WTW e YSI. No laboratório foram determinados alcalinidade $\left(\mathrm{cmol} \mathrm{kg}{ }^{-1}\right)$; dureza total $\left(\mathrm{mg} \mathrm{L}^{-1} \mathrm{CaCO}_{3}\right)$; acidez total ( $\mathrm{mg}$ $\left.\mathrm{L}^{-1}\right)$; cloreto $\left(\mathrm{mg} \mathrm{L}^{-1}\right)$; demanda química de oxigênio (DQO $\left.\mathrm{mg} \mathrm{L}^{-1}\right)$; demanda biológica de oxigênio ( $\left.\mathrm{DBO}_{5-20} \mathrm{mg} \mathrm{L}^{-1}\right)$; resíduo total $\left(\mathrm{mg} \mathrm{L}^{-1}\right)$; fósforo, nitrogênio e ferro totais $(\mathrm{mg}$ $\mathrm{L}^{-1}$ ), e coliformes termotolerantes (NMP $100 \mathrm{~mL}^{-1}$ ) segundo APHA (2005). A Resolução Conama no 357 de 17/03/2005 (Conama 2005) foi utilizada como base de comparação dos dados obtidos e, a partir dos resultados, foi gerado o IQA - Índice de Qualidade da Água para a área de estudo. Um diagnóstico da qualidade ambiental foi elaborado dando ênfase a identificar áreas de risco de erosão e assoreamento pela destituição da mata ciliar considerada Área de Proteção Permanente - APP às margens do rio Parauapebas. 


\section{RESULTADOS E DISCUSSÃO}

Não há propriamente uma classificação das águas na região, entretanto, considerando ter se verificado entre seus usos preponderantes a recreação de contato primário, foi conveniente enquadrá-la na classe II da Classificação dos Corpos de Água da Resolução Conama no 357 (Conama 2005). A definição da classe de enquadramento das águas é condição preponderante para se estabelecer, ao longo da discussão, os limites permissíveis de cada parâmetro ambiental analisado. Os valores médios e de tendência dos parâmetros ambientais das águas superficiais do rio Parauapebas no trecho estudado estão apresentados na Figura 2. Uma avaliação com base na Resolução Conama no 357 (Conama 2005) revelou um comprometimento pontual (localizado) da qualidade da água em decorrência de lançamentos de efluentes e resíduos sólidos, devendo-se aqui destacar algumas tendências. A transparência da água apresentou uma ligeira variação nos seus valores, oscilando entre 0,43 e 0,95 m com média de $0,80 \pm 0,09 \mathrm{~m}$. A transparência um pouco mais elevada do que o normal para águas claras foi decorrente do período de monitoramento, que coincidiu com a época de menor precipitação, consequentemente menor contribuição fluvial, pequena lixiviação das áreas adjacentes e baixa taxa de material em suspensão, com resíduo total médio de $8,05 \pm 2,41 \mathrm{mg} \mathrm{L}^{-1}$.

Os teores de oxigênio dissolvido variaram entre 2,60 e 4,40 $\mathrm{mg} \mathrm{L}^{-1}$ (média de 3,85 $\pm 0,31 \mathrm{mg} \mathrm{L}^{-1}$ ), permanecendo todo o tempo abaixo do limite mínimo de $5 \mathrm{mg} \mathrm{L}^{-1}$ estabelecido pela
Resolução Conama para águas de Classe II. Os maiores valores foram determinados para os pontos 2 , 4 e $5\left(-4,4 \mathrm{mg} \mathrm{L}^{-1}\right)$, enquanto que as menores concentraçóes foram encontradas no ponto $6\left(-2,6 \mathrm{mg} \mathrm{L}^{-1}\right)$ na saída do Igarapé Ilha do Coco. As baixas concentraçóes de OD coincidem com a alta turbidez (> 24 NTU) e baixa transparência $(<0,50 \mathrm{~m})$, decorrente do lançamento de efluentes contendo elevada carga de material em suspensão e matéria orgânica. Deve-se mencionar que, a partir do momento em que as águas provenientes do Igarapé Ilha do Coco se misturam com as águas do rio Parauapebas, os valores de turbidez tendem a diminuir até a estabilização. Os valores de $\mathrm{pH}$ oscilaram entre 6,93 no ponto 20 , já na saída da cidade, e 7,60 no ponto 17, a jusante do Estádio de Futebol, com média 7,28 $\pm 0,12$, não superando os limites da Resolução Conama no.357 (Conama 2005), que estabelece valores de $\mathrm{pH}$ para rios de classe II entre 6,0 e 9,0. Deve-se ressaltar que é comum nas águas amazônicas mensurar um pH mais baixo, especialmente para as águas pretas e eventualmente paras as águas claras, como é o caso do rio em questão. A pequena variação no $\mathrm{pH}$, entretanto, revelou uma ótima capacidade de tamponamento pelo ecossistema, de modo que, os valores determinados do $\mathrm{pH}$ variaram de uma faixa ligeiramente ácida, devido principalmente à contribuição da bacia de hidrográfica e decomposição da matéria orgânica, até ligeiramente alcalina, devido principalmente à contribuição geológica da região. A curva de tendência para o $\mathrm{pH}$ (Figura 2) demonstrou que parâmetro este oscilou entre 7,2 e 7,3 dentro da área

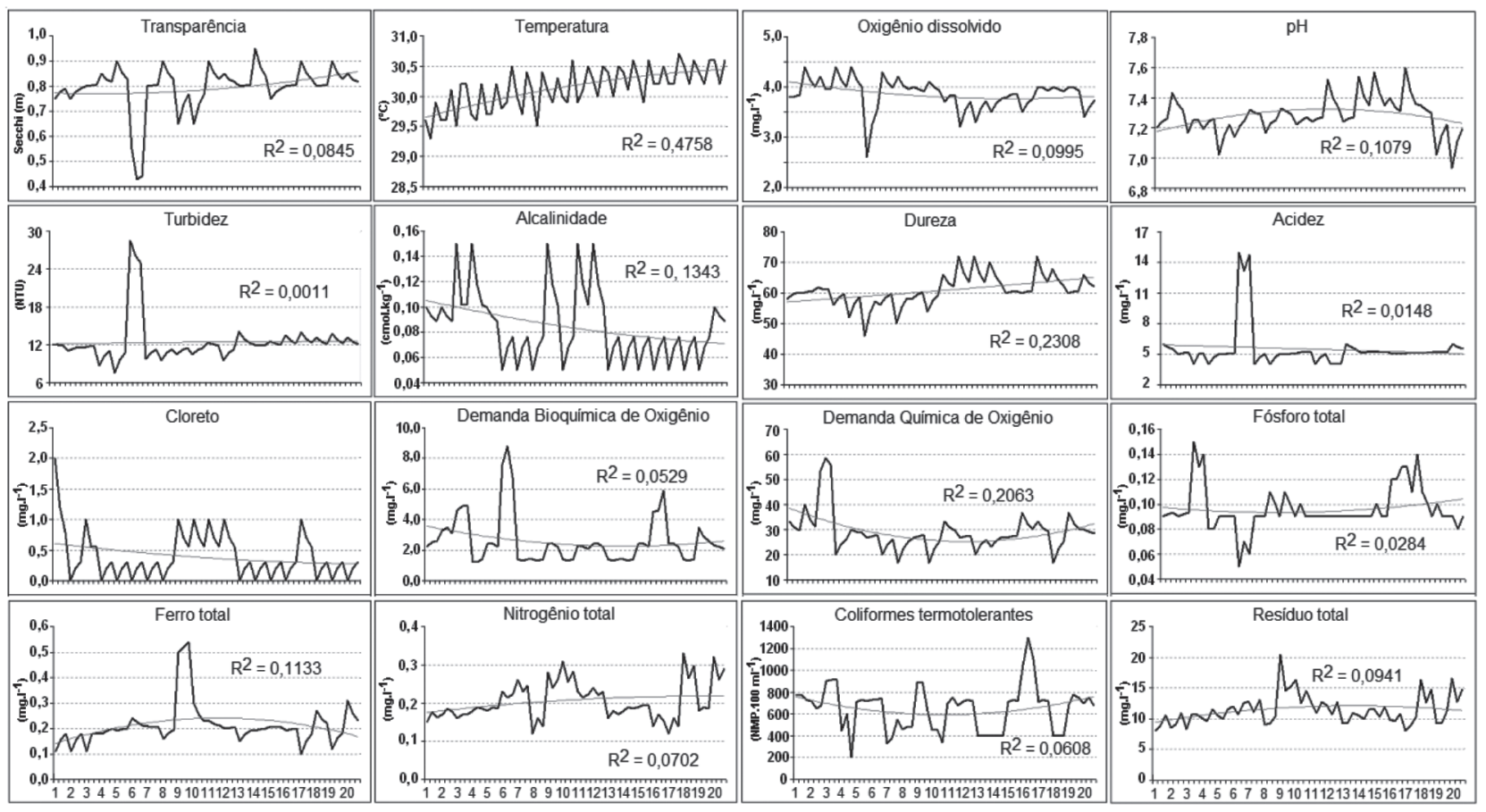

Figura 2 - Dados médios da variabilidade espacial dos parâmetros limnológicos estudados na água superficial do rio Parauapebas entre 2004 e 2009 . Destaque para a curva de tendência (cinza) e variância. 
monitorada. Quando se compara os valores encontrados com o limite de turbidez estabelecido na Resolução Conama no 357 (Conama 2005) se observa que em todos os pontos os valores determinados não ultrapassaram o teor permissível. Água límpida isenta de turbidez é importante quando ela se destina direta ou indiretamente ao consumo humano ou processos industriais, sendo que, turbidez acima de 5 NTU além de ser notada pelo consumidor e representar uma condição insatisfatória, dificulta o processo de desinfecção/esterilização por tratamento com radiação U.V. (Aprile e Siqueira 2011).

Embora seja notório que o rio sofra influência de despejo de esgoto doméstico, as águas monitoradas apresentaram valores poucos expressivos de alcalinidade total, cujos teores oscilaram entre 0,05 e $0,15 \mathrm{cmol} \mathrm{kg}^{-1}$ com média $0,08 \pm$ $0,03 \mathrm{cmol} \mathrm{kg}^{-1}$. Os valores de dureza encontrados oscilaram entre 46,00 $\mathrm{mg} \mathrm{L}^{-1}$ (ponto 6) e 72,00 $\mathrm{mg} \mathrm{L}^{-1}$ (pontos 12 e 17, respectivamente), com média de $60,90 \pm 4,93 \mathrm{mg} \mathrm{L}^{-1}$. Quando se observa os valores médios determinados no trabalho atual, pode-se sugerir uma classificação dessas águas como moderadamente mole, de acordo com a classificação abordada por Langelier, 1994 apud Rocha et al. (2004). No aspecto acidez total, os valores oscilaram aproximadamente entre 4,0 e 6,0 $\mathrm{mg} \mathrm{L}^{-1}$, com linha de tendência próxima de 5,0 $\mathrm{mg} \mathrm{L}^{-1}$ mostrando um padrão bastante conservativo para o sistema. A exceção mais uma vez foi para o ponto 6 , na saída do Igarapé Ilha do Coco, onde os valores detectados ficaram próximos de $15 \mathrm{mg} \mathrm{L}^{-1}$. Esse valor pode estar associado à influência local, como a presença de esgotos domésticos ao longo do leito do igarapé. Valores de cloreto muito abaixo do limite admitido pela Resolução Conama no 357 (Conama 2005) que é de $250 \mathrm{mg} \mathrm{L}^{-1}$, foram encontradas ao longo da série amostral do rio Parauapebas. Sendo que no presente trabalho a média encontrada foi de $0,40 \pm 0,39 \mathrm{mg} \mathrm{L}^{-1}$ de cloretos na águas.

$\mathrm{O}$ rio Parauapebas, dentro do trecho monitorado, recebe aporte de matéria orgânica e sedimentos, de modo que a decomposição dos compostos orgânicos por bactérias aeróbias tem contribuído para redução do oxigênio dissolvido e degradação da qualidade da água. Os valores de oxigênio consumido biológica (DBO) e quimicamente (DQO) oscilaram entre 2,20 e 9,79 $\mathrm{mg} \mathrm{L}^{-1}$ (média 3,83 $\pm 1,87 \mathrm{mg} \mathrm{L}^{-1}$ ) e entre 14,40 e 59,76 $\mathrm{mg} \mathrm{L}^{-1}$ (média 27,67 $\pm 10,88 \mathrm{mg} \mathrm{L}^{-1}$ ), respectivamente. Foram encontrados valores superiores aos limites permissíveis na Resoluçáo nº.357 (Conama 2005) para águas da Classe II para DBO nos pontos 3, 16 e 6, em ordem crescente, enquanto que o maior teor de DQO for observado no ponto 3. As reaçôes de oxidação da matéria orgânica e inorgânica no sistema, mediante conversão de gás carbônico e água, estão ocorrendo de forma mais localizada nas áreas de maior concentração urbana, o que consequentemente significa maior produçáo e liberação de efluentes, especialmente de origem doméstica.
Dentre os macronutrientes, o fósforo se destacou por apresentar uma variabilidade mais localizada (pontual), com os maiores valores entre $0,13-0,15 \mathrm{mg} \mathrm{L}^{-1}$ para os pontos 3 , 16 e 17. A linha de tendência central, entretanto, permaneceu próxima de $0,10 \mathrm{mg} \mathrm{L}^{-1}$ (média de $0,10 \pm 0,02 \mathrm{mg} \mathrm{L}^{-1}$ ). No Igarapé Ilha do Coco (ponto 6), as concentraçôes de fósforo total determinadas foram as menores detectadas em todo o sistema $\left( \pm 0,05 \mathrm{mg} \mathrm{L}^{-1}\right)$. Devido à complexa conformidade dos ecossistemas amazônicos, formados por um sistema fluvial com tributários lênticos e lóticos, fica difícil estabelecer um único limite permissível para fósforo total de acordo com a Resoluçáo Conama vigente, devendo ora ser adotado o limite de $0,025 \mathrm{mg} \mathrm{L}^{-1}$, que é destinado a ambientes intermediários com tempo de residência entre dois e 40 dias, e tributários diretos de ambiente lêntico, e ora o limite de $0,1 \mathrm{mg} \mathrm{L}^{-1}$ destinado a ambientes lóticos com tributários de ambientes intermediários. De qualquer forma, no rio Parauapebas ao longo do trecho estudado a totalidade dos pontos amostrados apresentou níveis de fósforo total acima dos limites da resoluçáo Conama. O comportamento e a distribuição do fósforo na coluna de água estão sujeitos a fatores bióticos (consumo por fitoplâncton) e abióticos (Melo 1998; Dantas et al. 2009), sendo que as reaçôes de formação de fosfato em associação com os íons $\mathrm{Ca}$, Fe e $\mathrm{Mg}$ dependem especialmente do $\mathrm{pH}$ do meio. Para o ferro total a linha de tendência ficou próxima de $0,2 \mathrm{mg} \mathrm{L}^{-1}$ sendo que o destaque foi o ponto 9, localizado na direção entre Hospital Estadual e a Prefeitura, com concentraçôes médias de $0,52 \mathrm{mg} \mathrm{L}^{-1}$, mostrando-se acima do valor permitido para ferro dissolvido pela Resolução Conama que é de $0,3 \mathrm{mg} \mathrm{L}^{-1}$ Comumente, o ferro é encontrado em águas claras em pequenas quantidades. Assim, uma interpretação para o fato pode ser atribuída à retirada de solos e sedimentos na área para construção. A fragmentaçáo das rochas da bacia de drenagem contribui para elevação dos níveis de ferro, tanto na forma dissolvida como particulada, está última associada principalmente a sedimentos argilosos. O nitrogênio total oscilou entre 0,12 e $0,33 \mathrm{mg} \mathrm{L}^{-1}$ com média de $0,20 \pm 0,05 \mathrm{mg} \mathrm{L}^{-1}$. Os destaques ficaram com os pontos $7,9,10,18$ e 20 com concentraçóes superiores à média e o ponto 8 com teores inferiores à mesma. Não há um limite definido para nitrogênio total na Resolução Conama vigente, muito embora o $\$ 3^{\circ}$ do artigo $10^{\circ}$ para águas doces de classes 1 e 2, leia-se que quando o nitrogênio for fator limitante para eutrofização, nas condiçôes estabelecidas pelo órgão ambiental competente, o valor do nitrogênio total (após oxidação) não deverá ultrapassar $2,18 \mathrm{mg} \mathrm{L}^{-1}$ para ambientes lóticos, na vazão de referência. Não há um padrão definido para a distribuição de nitrogênio nos ecossistemas aquáticos, de modo que essa distribuição dependerá de vários fatores, entre eles, o balanço entre as formas nitrogenadas, estratificação térmica e/ou química, densidade de organismos 
fotossintetizantes, em especial os fitoplanctônicos, volume de chuvas e naturalmente volume de material de origem alóctone, especialmente de origem antrópica. Nas condiçóes naturais da região Amazônica fatores como: as imensas dimensôes fluviais e conseqüentes grandes vazóes, a complexa rede de fluxo de nutrientes e energia decorrente das interaçóes aquáticoflorestais, o volume de material orgânico em circulaçáo e a imensa capacidade de depuração do corpo receptor fazem com que o nitrogênio, sob suas formas orgânica e inorgânica, esteja sempre circulando pelos diversos componentes biótico e abiótico, dificilmente atuando como fator permanentemente limitante à eutrofização. Nos ecossistemas terrestres, o nitrogênio é considerado o principal elemento limitante para o desenvolvimento das plantas. Esse padrão, entretanto, não se repete com frequência nos ecossistemas aquáticos, onde é o fósforo que geralmente exerce esse papel. Com base na razão $\mathrm{N}: \mathrm{P}$ calculada para a área de estudo, nota-se não haver um enriquecimento de nitrogênio no ecossistema aquático, estando este sempre próximo do limite de disponibilidade. A razáo N:P oscilou entre 1:1 (ponto 17) e 4:1 (ponto 6), permanecendo muito abaixo da razão média estabelecida para ecossistemas aquáticos continentais, que segundo Said et al. (2004) geralmente não excede 16:1. Essa é uma condição, no entanto, comum nos corpos de água da Amazônia, onde as grandes reservas nutricionais, especialmente dos macronutrientes, encontram-se na forma de biomassa nas plantas e, eventualmente, acumulada nos sedimentos em decorrência da decomposiçâo do material vegetal, mas nunca em grande quantidade na coluna de água.

Os coliformes termotolerantes, definidos na Resolução Conama no 357 como sendo bactérias gram-negativas e em forma de bacilos, que podem estar presentes em fezes humanas e de outros animais homeotérmicos, ocorrendo ainda em solos, plantas ou matrizes ambientais que não tenham sido contaminados por material fecal, são um importante parâmetro para determinação da qualidade da água de um sistema. No rio Parauapebas, durante o período de monitoramento, determinou-se concentraçóes entre 200 e $1300 \mathrm{NMP} 100 \mathrm{~mL}^{-1}$, com média de $650 \pm 207$ NMP 100 $\mathrm{mL}^{-1}$. Considerando o limite permissível para Classe II de 1000 coliformes termotolerantes por $100 \mathrm{~mL}$ em pelo menos $80 \%$ das amostras, pode-se concluir que apenas o ponto 16 ultrapassou o limite de referência, muito embora os pontos 3 e 9 tenham atingido valores muito próximos do limite e, a amostragem não tenha sido realizada com freqüência bimestral, como dita a Resolução Conama.

A análise de componentes principais (PCA, Figura 3) foi realizada com 16 variáveis determinadas na água do rio Parauapebas para o período de menor precipitação na região nos anos de 2004, 2007 e 2009, sendo gerado um Biplot entre as componentes 1 e 2 , que explicaram a distribuiçấo dos

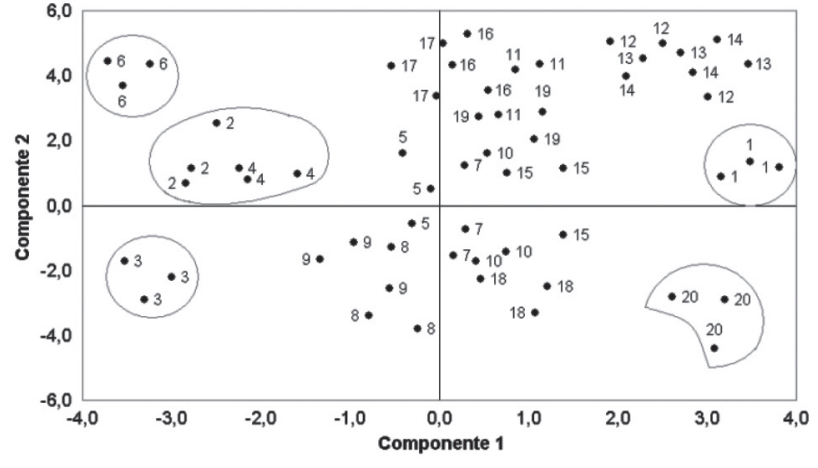

Figura 3. Inter-relação (biplot) entre a componente principal 1 (DBO, DQO e coliformes termotolerantes) e 2 (elementos iônicos) considerando as propriedades físicas, químicas e microbiológicas na água do rio Parauapebas - PA para os anos 2004, 2007 e 2009.

pontos com padróes de resposta em torno de $88 \%$, sendo que $\mathrm{OD}, \mathrm{DBO}$, fósforo total e coliformes termotolerantes foram responsáveis por explicar quase a totalidade dos resultados (75\%). A componente 1 , que separou espacialmente os pontos em função do consumo de oxigênio para degradação química e/ou biológica da matéria orgânica e pela variação dos contaminantes fecais, foi responsável pela maior parte da explicação da distribuiçáo espaço-temporal, sendo que $62 \%$ do total explicado por este componente tem peso positivo. A componente 2, por sua vez, separou espacialmente os pontos em função da variação dos elementos iônicos, especialmente fósforo. No Biplot, os pontos de amostragem $3,6,8,9,16$ e 17 foram os mais influenciados pelo fósforo e pela $\mathrm{DBO}$, sendo estes pontos de coleta os que mais se diferenciaram em termos de qualidade da água da bacia, havendo uma nítida dispersão e/ou repulsão espacial entre eles (Figura 3). Os pontos 1 e 20, por sua vez, se diferenciaram principalmente em função da localização, a montante e a jusante do município, respectivamente. A indicação do a) fósforo, um macronutriente de fundamental importância para os processos biológicos, e que pode atuar como fator limitante dentro do fluxo de energia; b) oxigênio, que além do fato de ser indispensável à vida aquática, sua concentração e solubilizaçáo no sistema dependem de fatores correlatos de ordem física (temperatura da água, concentração de sólidos totais, transparência, ação dos ventos etc.), química (reaçôes de oxiredução, decomposição da matéria orgânica etc.), e biológica (densidade de organismos fitoplanctônicos, atividade fotossintética etc.); além da indicação de dois parâmetros biológicos c) $\mathrm{DBO}$ e d) coliformes termotolerantes, que estão associados à presença de compostos orgânicos e contaminantes fecais no sistema, demonstra a necessidade de um maior investimento (esforço) para identificar os ativos e passivos ambientais, principalmente por atividade antrópica, responsáveis pela alteraçấo da qualidade da água da bacia no trecho estudado. 


\section{Índice de Qualidade da Água}

O Índice de Qualidade da Água (IQA) foi inicialmente desenvolvido pela National Sanitation Foundation dos Estados Unidos em 1970 (WQI - Water Quality Index). Posteriormente, a Companhia de Tecnologia de Saneamento Ambiental do Estado de Sáo Paulo (Cetesb), a partir de uma consulta a especialistas da área de saneamento decidiu incorporar o IQA em suas práticas de monitoramento das bacias hidrográficas do Estado, modificando a faixa de valores dos parâmetros considerados relevantes para a avaliação da qualidade das águas interiores, especialmente destinadas para abastecimento público (Cetesb 2010 a,b,c). O IQA tem sido considerado uma ferramenta de grande valia para classificação das águas superficiais, com base em parâmetros limnológicos previamente normalizados/padronizados (Pesce e Wunderlin 2000; Swamee e Tyagi 2000; Bordalo et al. 2001; Cude 2001; Nagel 2001; Jonnalagadda e Mhere 2001; Liou et al. 2003; Hernández-Romero et al. 2004; Sánchez et al. 2007). Tratase de um instrumento matemático usado para transformar um conjunto de dados limnológicos em uma representaçáo numérica do nível de qualidade de água em um determinado trecho de rio. Assim foram definidos os seguintes parâmetros: temperatura da água, $\mathrm{pH}, \mathrm{OD}, \mathrm{DBO}$, turbidez, fósforo total, nitrogênio total, resíduos totais e coliformes termotolerantes. O IQA determinado para o rio Parauapebas, dentro do trecho de referência, foi de 40,01, o que na classificação do Índice enquadra-se na categoria "Regular". Esse valor foi obtido a partir do cálculo da média aritmética de todos os índices, para cada ponto de amostragem, para os três anos de coleta. A análise pontual do IQA (Figura 4), náo obstante, não foi muito diferente do resultado geral, $70 \%$ dos pontos monitorados ficaram enquadrados na categoria "Regular". Isso vem significar que o rio Parauapebas, no trecho monitorado, já apresenta sinais de poluição antrópica e degradação ambiental, inspirando cuidados. Pode-se dizer ainda que o rio começa a sofrer com a pressão urbana em seu entorno, necessitando urgentemente de um programa de recuperação para as áreas degradadas, em especial as matas ciliares, que foram quase totalmente destituídas dos seus locais de origem.

Procurando identificar qual ou quais, das nove variáveis que compóem o IQA, tiveram maior "peso" ou grau de significância para a geração do índice, aplicou-se, paralelamente a PCA, a análise de regressão múltipla. Corroborando, em parte, com a análise de componentes principais (Figura 3), a análise da regressão múltipla, responsável por avaliar o comportamento simultâneo das variáveis monitoradas em relação ao IQA, revelou que coliformes termotolerantes e $\mathrm{DBO}$ foram as variáveis que melhor se correlacionaram em conjunto $\left(\mathrm{R}^{2}=0,5876 ; \mathrm{p}<0,05 ; \mathrm{F}=16,8412 ; \mathrm{n}=60\right)$. Já o oxigênio dissolvido e fósforo total, apesar de apresentarem

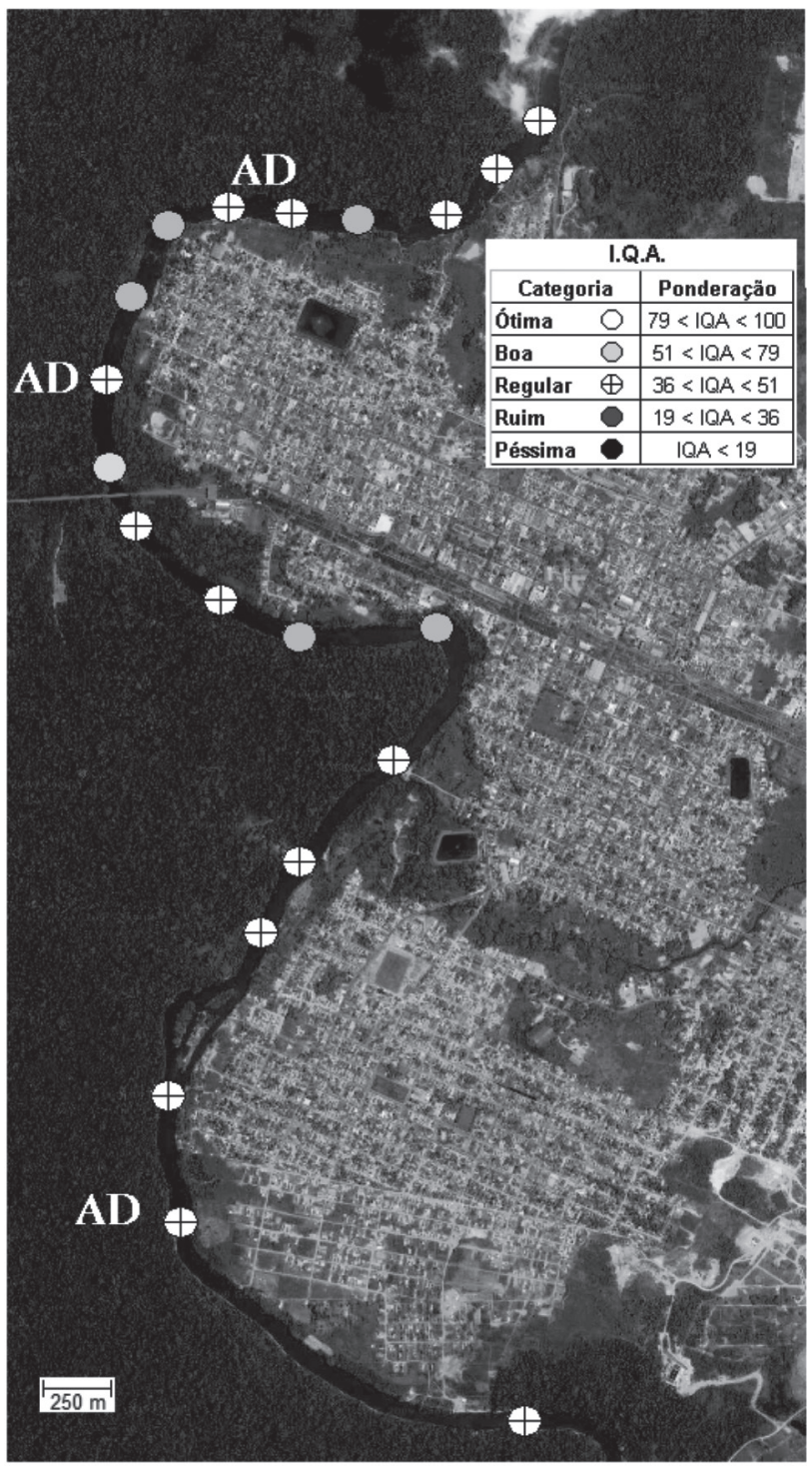

Figura 4 - Índice de Qualidade das Águas do rio Parauapebas no entorno do município de Parauapebas para o período de 2004 a 2009. Legenda: AD = Área mais degradada com sugestão de intervenção para programa de revitalização. (Fonte: 2011 Google - Imagens (C2011 DigitalGlobe, GeoEye, Cnes/Spot Image).

alguma correlação individual significativa com o IQA, visto que também fazem parte no calculo do índice, não apresentaram correlaçáo conjunta significativa na regressão múltipla. A análise de regressão linear entre a variável "dependente" coliformes termotolerantes e o índice gerado $\left(R^{2}=0,4834, p \leq 0,0007\right.$; Figura 5) revelou ser essa variável a mais significativa para a interpretação da qualidade da água da bacia no trecho monitorado. Esse resultado reforça a questão de estar havendo contaminação por efluentes orgânicos na 

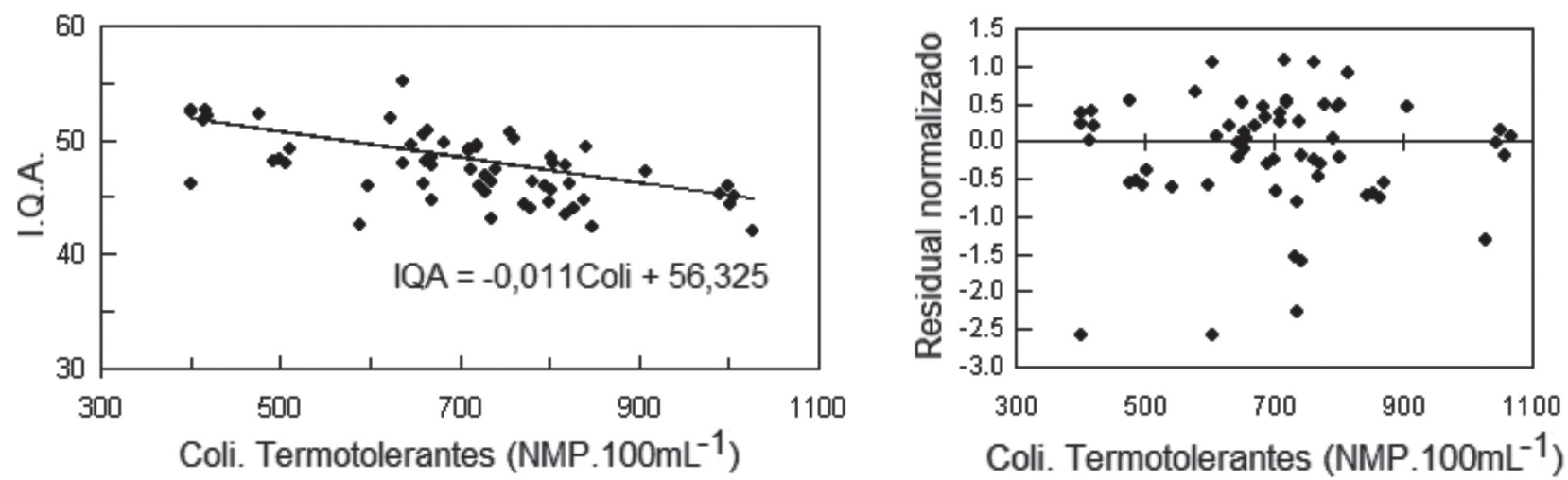

Figura 5 - Análise de regressão linear entre coliformes termotolerantes e IQA, com respectiva análise residual normalizada.

região, especialmente de origem doméstica, necessitando de atenção especial por parte dos administradores municipais no que tange ao saneamento básico.

A partir do diagnóstico da qualidade ambiental da bacia foram identificadas duas áreas (ver Figura 4), que merecem especial atenção devido à degradação do meio ambiente, produção e descarte de efluentes e, especialmente, desmatamento da vegetação marginal pela expansão urbana, fato que traz como conseqüência o risco de erosão e assoreamento de trechos do rio. Essas áreas são: 1) o trecho norte-noroeste (N-NO) da cidade, onde há uma expansão urbana em direção à margem direita do rio, onde também está localizada a Prefeitura Municipal e cujo limite inferior é a estrada estadual PA-276, e 2) o trecho sul-sudoeste (S-SO), onde algumas ruas chegam bem próximo à margem do rio Parauapebas. Espera-se que, de posse de tais informaçóes, os administradores do município possam desenvolver um plano de ação para revitalização das áreas mais degradadas da cidade, o que deve incluir os igarapés urbanos e os trechos do rio Parauapebas apontados neste trabalho.

Concluí-se que um volume considerável de carga orgânica aporta para a área estudada no rio Parauapebas, demonstrada pela redução nos níveis de oxigênio molecular dissolvido, devido principalmente à degradação promovida pelas bactérias aeróbias. Grande parte do material orgânico e inorgânico que atinge o leito do rio provém do conglomerado urbano existente. A evidência de que efluentes sanitários atingem o curso de água está demonstrada na contribuiçáo do Igarapé do Coco para o sistema, pois uma parcela significativa de matéria orgânica biodegradável tem seus valores incrementados à desembocadura desse afluente.

As análises de componentes principais e de regressão múltipla identificaram a demanda bioquímica de oxigênio, coliformes termotolerantes, fósforo total e a própria concentração de oxigênio molecular dissolvido na água como sendo fatores determinantes na identificação de focos de contaminação e poluição, especialmente por esgotamento sanitário.

O desmatamento das matas ciliares, atividades mineradoras, retirada de sedimento (seixo) para construção civil e a expansão urbana não planejada têm causado impactos pontuais no rio Parauapebas. Os igarapés que cortam a cidade começam a apresentar sinais de degradação e poluição, sendo que estes acabam por desaguar no rio em questáo. Entretanto, pelas condiçóes hidrodinâmicas observadas, destacando-se velocidade de fluxo e corrente de maré, as águas do rio têm plenas condiçóes de se autodepurar, desde que o processo de degradação seja controlado. Ao julgar pelas condições dos recursos hídricos de outras bacias hidrográficas submetidas à ação antropogênica, infere-se que a qualidade das águas do rio Parauapebas ainda encontra-se em plenas condiçóes de uso e reúso. O Índice de Qualidade da Água aplicado aos resultados, no entanto, demonstra que a maioria dos pontos monitorados encontra-se em estado de alerta, visto que 70\% destes ficaram enquadrados na categoria "Regular".

Torna-se necessário o planejamento e aplicação de açóes para minimizar os impactos ambientais apontados e recuperar a qualidade da água do rio Parauapebas. Para tanto, é fundamental a criação de um banco de dados tendo em vista a identificação dos ativos e passivos ambientais, não apenas a nível macro, mas também a nível pontual. Só assim, será possível aplicar medidas realmente efetivas para recuperação da qualidade ambiental da bacia.

\section{BIBLIOGRAFIA CITADA}

Agência Nacional das Águas - ANA. 2002. A evolução da gesta dos recursos hidricos no Brasil. ANA: Brasília - DF. 68 pp.

Agência Nacional das Águas - ANA. 2005. Panorama da qualidade das águas superficiais no Brasil. Cadernos de Recursos Hídricos, 1, ANA/MMA: Brasília - DF. 176 pp.

APHA/AWWA/WEF. 2005. Standard methods for examination of water and wastewater. American Public Health Association, 
American Water Works Association and Water Environment Federation. $21^{\text {st }}$ ed., Washington, USA. 4358 pp.

Aprile, F.M.; Siqueira, G.W. 2011. Alternative treatment methods of drinking-water for river communities in Central Amazoniam, p.1143-1166. In: Bilibio, C.; Hensel, O.; Selbach, J. (Eds.). Sustainable Water Management in the Tropics and Subtropics - and Case Studies in Brazil. 10 ed. v.1. Fundação Universidade Federal do Pampa, Unikassel, PGCult/UFMA, Rio Grande do Sul.

Bordalo, A.A.; Nilsumranchi, W.; Chalermwat, K. 2001. Water quality and uses of the Bangpakong River (Eastern Thailand). Water Research, 35: 3535-3642.

Companhia de Tecnologia de Saneamento Ambiental do Estado de São Paulo - CETESB. 1988. Guia de coleta e preservação de amostras de água. CETESB, São Paulo. 64 pp.

Companhia de Tecnologia de Saneamento Ambiental do Estado de São Paulo - CETESB. 2010a. Qualidade das Águas Superficiais no Estado de São Paulo 2009. Série Relatórios/CETESB, São Paulo. 310 pp. (http://www.cetesb.sp.gov.br/agua/relatorios/ rios/rel_aguas_int_2009). Acesso em 10/01/2011.

Companhia de Tecnologia de Saneamento Ambiental do Estado de São Paulo - CETESB. 2010b. Índices de Qualidade das Águas. Secretaria do Estado do Meio Ambiente, São Paulo. (http:// www.cetesb.sp.gov.br/userfiles/file/agua/aguas-superficiais/aguasinteriores/documentos/indices/01.pdf) Acesso em 01/02/2011.

Companhia de Tecnologia de Saneamento Ambiental do Estado de São Paulo - CETESB. 2010c. Índices de Qualidade das Águas. Secretaria do Estado do Meio Ambiente, São Paulo. (http:// www.cetesb.sp.gov.br/userfiles/file/agua/aguas-superficiais/aguasinteriores/documentos/indices/02.pdf) Acesso em 01/02/2011.

Conselho Nacional do Meio Ambiente-CONAMA. 2005. Resolução $n^{o}$. 357, de 17 de março de 2005. CONAMA, MMA, 23 pp. (http://www.cetesb.sp.gov.br/Agua/praias/res_conama_357_05. pdf) Acesso em 14/01/2011.

Cude, C. 2001. Oregon water quality index: a tool for evaluating water quality management effectiveness. Journal American Water Research Association, 37: 125-13.

Dantas, E.W.; Almeida, V.L. dos S.; Barbosa, J.E. de L.; BittencourtOliveira, M. do C.; Moura, A. do N. 2009. Efeito das variáveis abióticas e do fitoplâncton sobre a comunidade zooplanctônica em um reservatório do Nordeste brasileiro. Iheringia, 99(2): 132-141.

Goulding, M.; Barthem, R.; Ferreira, E. 2003. The Smithsonian atlas of the Amazon. Princeton Editorial Associate, Inc. Hong Kong. 253 pp.
Hernández-Romero, A.H.; Tovilla-Hernández, C.; Malo, E.A.; BelloMendoza, R. 2004. Water quality and presence of pesticides in a tropical coastal wetland in southern Mexico. Marine Pollution Bulletin, 48: 1130-1141.

Instituto Brasileiro de Geografia e Estatística - IBGE. 2010. IBGE Cidades@. (http://www.ibge.gov.br/cidadesat/topwindow.htm?1) Acesso em 01/02/2011.

Jonnalagadda, S.B.; Mhere, G. 2001. Water quality of the Odzi river in the eastern highlands of Zimbabwe. Water Research, 35: 2371-2376.

Liou, S.M.; Lo, S.L.; Hu, C.Y. 2003. Application of two-stage fuzzy set theory to river quality evaluation in Taiwan. Water Research, 37: 1406-1416.

Melo, O.T. 1998. Comportamento biogeoquimico de nutrientes no estuário do rio Bocanha ilha de São Luis - MA. Dissertaçáo de Mestrado em Geoquímica, UFPA, Belém, Pará. 210 pp.

Nagel, J.W. 2001. A water quality index for contact recreation. Water Science Technology, 43: 285-292.

Pesce, S.F.; Wunderlin, D.A. 2000. Use of water quality indices to verify the impact of Cordoba City (Argentina) on Suquia River. Water Research, 34: 2915-2926.

Prefeitura Municipal de Parauapebas - P.M.P. 2009. Informaçōes, turismo e diversão. Coordenadoria de Informática - SEFAZ/ Assessoria de Comunicação Social. (http://www.parauapebas. pa.gov.br) Acesso em 24/01/2011.

Rocha, J.C.; Rosa, A.H.; Cardoso, A.A. 2004. Introdução a Química Ambiental. Editora Bookman, Porto Alegre. 154 pp.

Said, A.; Stevens, D.; Sehlke, G. 2004. Relation of land-use to total nitrogen/phosphorus in streams. (http://emrc.usu.edu/tmdl/ ineel/abstracts/papernp.pdf) Acesso em 26/03/2011.

Sánchez, E.; Colmenarejo, M.F.; Vicente, J.; Rubio, A.; García, M.G.; Travieso, L.; Borja, R. 2007. Use of the water quality index and dissolved oxygen deficit as simple indicators of watersheds pollution. Ecology Indicators, 7: 315-328.

Swamee, P.K.; Tyagi, A. 2000. Describing water quality with aggregate index. Journal Environment Engineering, 126: 451-455.

Tundisi, J.G. 2003. Água no século XXI: Enfrentando a escassez. Editora Rima, São Paulo. 247 pp.

Recebido em: 06/02/2011

Aceito em: 15/09/2011 
